\title{
Sexo sin reproducción y reproducción sin sexo. Sexualidad y salud reproductiva de los donantes de semen y óvulos
}

\author{
Sex Without Reproduction and Reproduction Without Sex. \\ Sexuality and the Reproductive Health \\ of Sperm and Egg Donors.
}

\author{
Consuelo Álvarez Plaza \\ Universidad Complutense
}

\section{RESUMEN}

Las técnicas de reproducción humana asistida (TRHA) surgen en los años 70 para solucionar problemas de esterilidad. Los avances en este campo abrieron múltiples opciones para parejas heterosexuales con problemas de fertilidad y para otros grupos que vieron cubrir sus expectativas para acceder a la maternidad/paternidad en cualquier momento de su ciclo vital y/u obviando el coito reproductivo. El acceso de nuevos grupos (parejas homosexuales, mujeres y hombres sin pareja, acceso tardío a la maternidad), ha provocado un aumento de la necesidad de gametos de donantes. Esta propuesta presenta una investigación llevada a cabo en clínicas de reproducción asistida de la Comunidad de Madrid (España). Se mostrará cómo se ejerce un control sobre los y las donantes quedando sus cuerpos disociados como meros reproductores al servicio de las necesidades y deseos de maternidad y/o paternidad de otros. Se pondrá de manifiesto las consecuencias para el donante de semen y la donante de óvulos relacionadas con la modificación de sus hábitos sexuales y las repercusiones en la salud reproductiva en el caso de las donantes.

Palabras clave: Donantes semen; Donantes Óvulos; Reproducción humana; Hábitos sexuales; Salud Reproductiva.

\section{SUMMARY}

Human-assisted reproductive technology (HART) appeared in the 1970s to help resolve sterility problems. Advances in this field opened up multiple options both for heterosexual couples with fertility problems and for other groups who saw the opportunity to access maternity/paternity at any point in their lifestage and/or without the need for reproductive coitus. The access of new groups (homosexual couples, men and women without partners, late access to maternity...) has led to an increased need for gamete donors. This paper presents research conducted in assisted reproduction clinics in the Autonomous Region of Madrid in Spain. The research shows the control process exercised with male and female donors, whose bodies are dissociated in order to act as mere reproducers who meet the maternity and/or paternity needs and wishes of others. We will refer both to the consequences for egg and semen donors in terms of the modification of sexual habits, and to the repercussions for the reproductive health of egg donors.

Key words: Semen Donors; Egg Donors; Human Reproduction; Sexual Habits; Reproductive Health. 


\section{INTRODUCCIÓN}

Las técnicas de reproducción humana asistida (TRHA) con la participación de un donante reproductivo (TRHA-D) ha suscitado numerosas investigaciones en la antropología, donde se ponen de manifiesto múltiples cuestiones:la preeminencia de la vertiente social sobre la genética/biológica, (Ragoné 1994; Hammer 1992), la esencialización de los genes (Bestard 2004), la asimetría en el ámbito del género (Stolcke 2004), la reideologización del papel de la biología en las relaciones humanas (Strathern 1992; Edwards 2005) o el mercantilismo en la donación de gametos (Tober 2001; Álvarez 2008), entre otros. Los análisis de investigadores sociales sobre la voluntariedad y las constantes llamadas a relativizar el sistema de engendramiento, patente en las técnicas de donación-recepción de gametos, abren un interesante debate sobre si se debe visibilizar o eludir la participación de los y las donantes. Existen varios aspectos de esta participación muy diferentes, por un lado si se debe revelar o no a los hijos el modo en que han sido engendrados y por otro lado si se debe levantar el anonimato de los y las donantes lo que permite el acceso a la identidad del donante. En este caso el hijo agámico o semiagámico ${ }^{1}$ puede, si así lo desea, conocer a su genitor/a o donante sin que ello implique ningún tipo de relación ni responsabilidad parental por ambas partes. Países europeos como Bélgica, Dinamarca, Holanda, Noruega, Reino Unido, Suecia, Suiza, han legislado para eliminar el anonimato de los donantes, permitiendo que los niños nacidos mediante su intervención puedan conocer su origen genético. Fuera de Europa podemos señalar Estados Unidos de Norteamérica y Nueva Zelanda con similar legislación. Por el contrario, en España la Ley 14/2006 sobre Técnicas de Reproducción Asistida asegura el anonimato del y la donante, con lo que se protege la identidad de estos y permite que los receptores, al menos las parejas heterosexuales, puedan ocultar en su medio social y familiar la participación de un tercero en el engendramiento de su hijo.

Las investigaciones de expertos sociales y en el ámbito de la salud en torno a revelar o no el origen genético a los hijos nacidos por TRHA-D han sido muy significativas en la última década tanto en España (Fitó 2010; Álvarez 2014) como a nivel internacional (Miller 2008; Daniels et al. 2009, entre otros). Importante señalar los diferentes posicionamientos sobre la revelación de los orígenes según la estructura familiar heteroparental, monoparental, homoparental (Jouannet et al. 2010; Blake et al. 2010). La narrativas utilizadas también es un tema de interés para los investigadores sociales (Blake et al. 2010 y Jociles y Poveda 2015)2.

Otras cuestiones importantes que afectan a los y las donantes como los efectos de la donación sobre su salud, vida sexual, social, laboral han sido menos estudiadas. En relación a las repercusiones en la salud como consecuencia de la donación de óvulos, no existen estudios a largo plazo basados en la evidencia científica de las

\footnotetext{
${ }^{1}$ El hijo semiagámico lleva la mitad de la aportación genética de uno de los padres y la otra mitad es de un donante de semen o de una donante de óvulos. En el caso de un hijo agámico, los genitores han sido un donante de semen y una donante de óvulos, por tanto no tiene ninguna vinculación genética con el padre y/o madre.

${ }^{2}$ La bibliografía es muy extensa, solo se muestran algunos autores, no es objetivo de este texto poner de manifiesto la problemática en torno a la revelación de los orígenes genéticos a los hijos/as nacidos mediante la donación de gametos.
} 
consecuencias, riesgos y efectos secundarios de la donación de óvulos en la fertilidad de la propia de la donante, así mismo se minimizan los efectos sobre la salud en general como consecuencia de la estimulación hormonal de los ovarios y la extracción de óvulos mediante la punción de los ovarios (Coeytaux y Tober 2013). Si bien los consentimientos informados que deben firmar reflejan el listado de todos los riesgos derivados de la donación, es difícil precisar si realmente comprenden el alcance de los mismos (Álvarez 2008).

En reproducción asistida se desvincula la sexualidad de la reproducción, pero al mismo tiempo se tienen muy presentes las prácticas sexuales así como la orientación sexual de los usuarios tanto receptores como donantes. Existen consentimientos informados específicos para receptores en función del modelo familiar que desean formar, en pareja (heterosexual o lesbianas), o en solitario (mujeres solas) y normas específicas en relación a abstinencia sexual o a evitar determinadas prácticas sexuales para los y las donantes. Ante este control de la sexualidad, tan evidente, resulta llamativo que no existan registros antropológicos de las conductas y hábitos sexuales en las etnografías cuyos trabajos de campo se han desarrollado en centros de reproducción asistida.

El objetivo de este texto es dar a conocer algunas cuestiones silenciadas en las investigaciones cuantitativas y cualitativas sobre sexualidad y salud reproductiva de los donantes de semen y donantes de óvulos. Se mostrará las percepciones sobre la sexualidad de los donantes de semen y las donantes de óvulos, analizando los sistemas de captación, las normas sobre prácticas sexuales, consecuencias del incumplimiento de las mismas y las conductas y prácticas sexuales consideradas de riesgo para ser candidato. Para poner de manifiesto las consecuencias del acto de la donación de óvulos relacionadas con la salud sexual y reproductiva, me centraré en la supresión de métodos anticonceptivos, las dolencias y los posibles riesgos reproductivos derivados de los tratamientos y técnicas. Los datos etnográficos recopilados proceden de investigaciones llevadas a cabo en la Comunidad Autónoma de Madrid (España).

\section{EL TRABAJO DE CAMPO}

Los materiales etnográficos presentados son fruto del trabajo de campo desarrollado ininterrumpidamente del 2002 al 2005³, posteriores fases en el año $2009^{4}$ y en los primeros meses del $2013^{5}$. La recogida de datos se llevó a cabo en la Comunidad de Madrid, en dos centros de financiación privada (A y B) y dos de financiación pública (C y D) con datos procedentes de discursos, conductas y registros clínicos. Se

\footnotetext{
${ }^{3}$ Este periodo de investigación dio lugar a la tesis doctoral de la autora. Una versión de la tesis obtuvo el $2^{\circ}$ premio de investigación Marqués de Lozoya 2007.

${ }^{4}$ En el periodo de 2008-2011 se contó con el apoyo del proyecto "La reutilización de la cultura en las políticas de Intervención social" (referencia CSO2008-03427/SOCI) financiado por el Ministerio de Ciencia e Innovación de España.

${ }^{5}$ La investigación iniciada en el 2013 se está llevando a cabo dentro del proyecto "Revelación y secreto de los orígenes en las familias con descendencia por donación de gametos: variación según los modelos familiares" (referencia CSO2012-36413) del Plan Nacional de I+D+i financiado por el Ministerio de Economía y Competitividad de España.
} 
han realizado entrevistas en profundidad a 20 profesionales de la reproducción asistida, y a 52 donantes, 19 de semen y 33 de óvulos. Cada donante de semen y óvulo ha sido entrevistado en varias ocasiones, durante la primera visita a la clínica y en consultas sucesivas. Las entrevistas formales constituyen un punto de fricción para algunos actores. En este contexto de las clínicas de reproducción asistida ha resultado difícil investigar y entrevistar a los y las donantes. Si bien las charlas informales discurren con bastante normalidad, las entrevistas más estructuradas, con apoyo de grabadora y/o registro mediante notas, suele ser difícil por lo que se pierden muchas frases y comentarios ante la dificultad de registrarlos con exactitud. Las entrevistas fuera de la clínica son difíciles de llevar a cabo y se pierden muchos informantes captados en el centro.

\section{CONDICIONES PARA SER DONANTE DE GAMETOS.}

La selección de donantes de semen, entre 18 y $34^{6}$ años, tiene como objetivo asegurar el buen estado de salud de los donantes y la calidad de la muestra. La valoración del donante se hace desde dos puntos de vista: en el periodo de preaceptación, antes de formar parte del banco de semen, se realizan diversas pruebas y una entrevista personal (suele ser norma no aceptar como donante a quien ya lo ha sido en otra clínica $^{7}$ ); y en el periodo posaceptación, formando parte del banco de semen, se suele establecer el compromiso de 6 meses (como mínimo pero puede ser más tiempo) durante los cuales se recoge una muestra de semen por semana, obtenida por masturbación. A cada muestra se le hace seminograma para comprobar la capacidad fecundante del semen, se valoran parámetros como el número de espermatozoides, la morfología, la movilidad y la capacidad de recuperación tras ser sometidos a proceso de congelación. Las muestras de semen de donante suelen utilizarse tras un periodo de crioconservación, no siendo nunca utilizadas en fresco en el caso de semen de donante.

La donación de ovocitos se define como la técnica de reproducción asistida mediante la cual el gameto femenino es aportado por una mujer distinta a la que recibirá este o el embrión resultante. Las donantes deben tener entre 18 y 34 años y un buen estado de salud. Son sometidas a: pruebas diagnósticas previas para comprobar situación física y reproductora, posteriormente tratamiento hormonal durante 21-25 días para provocar estimulación ovárica y obtener varios folículos y por ultimo punción en quirófano con anestesia general o local en función del centro.

Los y las donantes deben firmar unos consentimientos informados donde de manera precisa se indican las condiciones de su donación y como sus gametos pasan a

\footnotetext{
${ }^{6}$ Los bancos de semen permiten superar esta edad al donante siempre que mantenga buen estado de salud y una capacidad espermática adecuada.

7 «El número máximo autorizado de hijos nacidos en España que hubieran sido generados con gametos de un mismo donante no deberá ser superior a seis" (Artículo 5.7 de la Ley 14/2006 de 26 de mayo sobre técnicas de reproducción humana asistida). A los efectos del mantenimiento efectivo de ese límite, los donantes deben comunicar que han pasado por otros centros, si así fuese la clínica o banco de semen debe asegurarse del número de niños nacidos del semen de ese donante para no superar lo que indica la normativa.
} 
ser gestionados por las clínicas siendo los profesionales quienes determinan el receptor adecuado del semen y/u óvulo, manteniendo en todo momento el anonimato. En el caso de la donante de óvulos, se especifica los riesgos que debe asumir durante el proceso como hiperestimulación ovárica, que consiste en una respuesta exagerada al tratamiento, infección, hemorragia o la torsión ovárica, si bien ocurren de manera excepcional.

\section{CONSTRUCIONES DE LOS CUERPOS OBJETO DE CONSUMO REPRODUCTIVO. PER- CEPCIONES SOBRE LA SEXUALIDAD DE LOS DONANTES.}

La cultura nos convierte en sujetos sexuales, todas las culturas socializan el cuerpo y las conductas sexuales. La educación sexual o sexologización (Vendrell 2003) es una forma de socialización que organiza la sexualidad en las sociedades occidentales y construye identidades. En las sociedades occidentales se reconoce la diversidad sexual pero es la heterosexualidad el modelo hegemónico (Gramsci 1982) vertebrado en torno a la reproducción y a la familia, quedando las otras conductas sexuales como subordinadas. La masculinidad hegemónica (Connell 1995: 76) se representa como dominante, poderosa constructora de jerarquías, legitimadora del patriarcado y heterosexual. Lógicamente la homosexualidad no resta fertilidad, pero desestabiliza el orden social vertebrador en torno a perpetuar la sociedad. Las TRHA conciben la sexualidad de los donantes de semen como una función corporal universal, estática, con una sexualidad joven estándar, "sexualidad genital de penetración que apuntala el falocentrismo" (Nieto 1990: 358-359).

Es interesante la percepción sobre la sexualidad de los y las donantes de gametos y las diferentes formas de publicitar para atraer a las clínicas a unos y a otras. Cuerpos que son percibidos como objeto de consumo reproductivo hipersexuados (y excelentes productores de semen) ellos y asexuadas (y reproductoras) ellas. El cuerpo de los y las donantes es publicitado como un espacio con mensajes cargados de belleza y salud, la publicidad resalta cualidades sobre el cuerpo donante de gametos que visibilizan la juventud, la fertilidad, el altruismo. Es un cuerpo que se convierte en objeto de consumo reproductivo (Aumont 1992). "A partir de la materialidad de nuestro cuerpo y del cuerpo de los otros, emergen discursos sobre la emoción que esos cuerpos generan en la mirada ajena, sobre la sexualidad, sobre el comportamiento, sobre la moral". (Enguix 2012: 175). El cuerpo reproductor del donante de semen no es un prototipo de lo humano, su funcionamiento se desliga de la experiencia cotidiana.

Si se hace una búsqueda de imágenes en internet introduciendo frases simples como donantes de semen y óvulos, aparecen jóvenes con cuerpos de belleza hegemónica. Las donantes ofrecen representaciones corporales asexuadas y reproductoras, imágenes de mujeres de más de 25 años que dan idea de mujer joven pero responsable y que sabe perfectamente lo que está haciendo. No es una mujer frágil, se refuerzan signos como ombligos al aire, colocación de las manos en el abdomen, caderas y cuerpos generosos, alejados de los prototipos de la industria de la moda. Cuerpos que muestran salud y un buen funcionamiento reproductivo. Un ginecólogo indicaba en la entrevista: 
Han evolucionado las imágenes que se ofrecen en la publicidad de las donantes de óvulos [...] no se incide en una mujer demasiado joven, por ejemplo de 18 a 25 años, ya que se puede concebir la idea de que será menos responsable en el tratamiento, puede abandonar el ciclo o saltarse alguna medicación. Una mujer algo mayor da idea de madurez emocional y social, y es posible pensar que se tome el asunto más en serio. El haber sido donante es un plus añadido y también el haber sido madre. Tal vez la imagen que se pretende ofrecer no es la de la joven universitaria, sino la mujer trabajadora, con hijos, que ha madurado su decisión de ayudar a otras mujeres. Sí, sí, tranquiliza más a todos. (Entrevista a ginecólogo RC, marzo 2009).

Las frases publicitarias hablan de generosidad, ayuda, felicidad, compartir. Algunos eslóganes son muy significativos, si bien en este texto no los vamos a analizar merecen por si mismos una reflexión. Desde los tópicos ayudar a otra mujer a ser madre, dar felicidad y esperanza donando óvulos, hasta frases con un mensaje más específico "todo lo que no se da se pierde, tus óvulos también" ", "tienes algo que te hace extraordinaria " ${ }^{9}$. Una clínica de reproducción asistida utiliza una imagen masculina para concienciar y atraer a las mujeres para que se hagan donantes de óvulos. Se dirige a las mujeres indicando que, a pesar de sus logros deportivos, hay algo que ellas pueden hacer y el no, "yo he podido ganar 3 ironmanes en 4 meses pero nunca podré donar óvulos. Tú que puedes dona óvulos»"

Los cuerpos para vender la imagen de donante de semen son más sexuados, con la promesa de ser buen reproductor y responde a varios de los supuestos sobre la sexualidad masculina que se ven encarnados en cuerpos masculinos jóvenes y aquí, cuanto más joven mejor. El hombre joven ofrece dos ventajas para la medicina reproductiva, calidad espermática y fácil respuesta física que acompaña a la actividad sexual. El cuerpo masculino, de manera reciente, ha sido cosificado (Rohlinger 2002) en occidente lo sexual impregna de manera importante la salud, las relaciones, las identidades. Pero además se privilegia el consumo (Giddens 1994, Schilling 2005). La masculinidad hegemónica (Connell 1995) aparece impregnada de mitos de manera esencialista y universal sobre el tamaño del pene, los hábitos sexuales, el deseo. Se produce una presión cultural para responder como se supone que debe hacerlo. Entre el imaginario y la realidad de la sexualidad masculina hay una serie de supuestos como la erección instantánea ante un estímulo erótico, siempre están dispuestos al sexo, no se preocupan de tener relaciones seguras, solo se excitan con cuerpos perfectos, el placer se obtiene solo con la eyaculación, etc. Es decir una sexualidad de urgencia, de inmediatez, de disponibilidad permanente ${ }^{11}$, de eyacula-

${ }^{8}$ Clínica Instituto Marqués http://www.institutomarques.com/donantes-ovulos.php (visitada el 26 julio 2013).

9 Se puede ver en http://sitio.nu/v3/publicidad/donacion-de-ovulos/ (visitada el 16 mayo 2013).

${ }^{10}$ El Ironman es la prueba más exigente del triatlón. Consta de 3,86 km de natación, $180 \mathrm{~km}$ de ciclismo y $42,2 \mathrm{~km}$ de carrera a pie (maratón). La carrera tiene un tiempo límite de $17 \mathrm{~h}$, un tiempo promedio de 12 horas. Marcel Zamora, campeón de triatlón se dirige a las posibles donantes de óvulos. Con este mensajehttp://www.dexeus.com/es_ES/salud-mujer-informacionmedicadetalle.aspx?a $=3 \& \mathrm{t}=53$ (visitada el 8 de enero 2011). Este tipo de publicidad en la que el hombre incita a la mujer se ha utilizado también en la campaña de detección precoz del cáncer de mama del año 2009 de la Asociación Española contra el Cáncer "iNo dices que por mí harías cualquier cosa? Hazte una mamografía"

${ }^{11}$ En la página web de una clínica se indica el tiempo que lleva al donante de semen la visita "aproximadamente 15 minutos por visita, excepto las primeras veces y al rellenar los consentimientos oportunos" https://www.ivi.es/donantes/donantes-semen/ (visitada el 8 de agosto de 2015). 
ción. La publicidad habla de la gran producción espermática del joven que es desaprovechada. Se alude a la producción "millonaria" de espermatozoides y a la pérdida. El altruismo que se explicita en la donación de óvulos pasa a ser dar lo que sobra en el caso de la donación de semen, "eres joven y te sobran millones", "todo lo que no se da se pierde"

La medicina reproductiva reconoce que el orgasmo autoinducido de la masturbación, en las condiciones psicológicas que tiene el varón en la clínica, produce un semen de "menor calidad espermática" en relación al coito o a una masturbación en condiciones más ideales. Los hombres cuyas parejas están sometidas a tratamiento de reproducción asistida también sienten la presión del control corporal por parte de la medicina reproductiva. Se espera de ellos que la muestra de semen se recoja a determinada hora. Debe estar el semen preparado en el laboratorio para fecundar los óvulos; como se prefiere utilizar el semen en fresco en estos casos (semen de la pareja o semen homólogo), este debe ser recogido casi coincidiendo con el momento de la punción de los folículos de la mujer. El lugar es poco adecuado para obtener la muestra; el hombre está nervioso y preocupado por su mujer. Estar tranquilo o nervioso influye en la calidad espermática. Esto es conocido por los hombres usuarios de la medicina reproductiva; es frecuente oír: "hoy no sé qué tal, no estoy inspirado", "Con los nervios es imposible, estoy pensando que llego tarde al trabajo", "es una faena que no esté hoy bien el semen después que están pinchando a mi mujer»" ${ }^{13}$. Sienten su responsabilidad y su esfuerzo menor que la mujer, pero se espera de ellos que la muestra de semen esté en las mejores condiciones.

Sé que es lo único que tengo que hacer yo, pero no es fácil... todo el mundo cree que los tíos nos masturbamos con facilidad y en cualquier momento. No es así; cuando sabes por lo que está pasando tu mujer en ese momento (la punción ovárica) se te quitan las ganas. El hecho de hacerlo aquí (baño) corta mucho. Si llevas más de cinco minutos alguien aporrea la puerta. joder! necesito un poco de tiempo ¿no? Yo no soy una maquina. (Entrevista a JC, marzo 2004).

Pero ¿qué ocurre con los donantes de semen? ¿Sienten la misma presión que las parejas masculinas de las mujeres sometidas a tratamientos en las clínicas? Para los usuarios y profesionales de las clínicas “los donantes de semen son hombres jóvenes, sanos, con actividad sexual normal y sin problemas para obtener la muestra de semen" (entrevista a ginecólogo LR, enero 2009). La actividad sexual normal es un término relativo y en función de la disciplina se ofrecen múltiples descripciones y definiciones de normalidad en el comportamiento sexual. Pero lo que nos interesa de la "Sexualidad normal" de los donantes no es cualquier práctica sexual, sino su capacidad para la masturbación. Y dar por hecho que todos los hombres la pueden practicar sin problemas es un error. En el "Informe Durex ${ }^{14}$ sobre bienestar sexual 2012" se recoge que la masturbación nunca la han practicado el 34\% de los hombres que par-

\footnotetext{
${ }^{12}$ Se puede consultar en http://www.institutomarques.com/donantes-semen.html (visitada el 26 de julio de 2013).

13 Testimonios recogidos en junio de 2005 y julio de 2009 de dos hombres cuyas mujeres han sido sometidas a TRHA

${ }^{14}$ Se recogen datos de encuestas a 29.000 personas mayores de 18 años, con amplia cobertura mundial (35 países). http://www.durex.com/es-ES/prensa/Documents/Cuadros\%20Informe\%20 Durex\%202012\%20\%281\%C2\%AA\%20Entrega\%29.pdf (visitado el 3 de agosto 2013).
} 
ticipan en la encuesta. La autosatisfacción sexual se considera como una actividad para el autoconocimiento y como alternativa ante la ausencia de pareja sexual o a edades precoces (infancia). El modelo heterosexual coitocéntrico sigue siendo dominante. La masturbación no se percibe como complementaria de las relaciones sexuales en pareja. Dado que lo que interesa es conocer si los donantes de semen tienen fácil la obtención de la muestra, pregunté en las clínicas si conocían referencias bibliográficas al respecto y si existían casos de dificultades en relación con la masturbación. "No hemos tenido ningún problema con los donantes, al menos no nos lo han indicado" (Entrevista a biólogo RH marzo 2012).

En medicina reproductiva se parte del modelo androcéntrico y heterosexual. En las clínicas se manifiesta una heterosexualización del deseo (Butler 2001), la manera de considerar que se va a producir la excitación sexual para obtener el preciado semen pasa por la idea de que todos los hombres que acuden a las clínicas, o bien con sus parejas como receptoras o bien como donantes, son heterosexuales. Las indicaciones, recomendaciones y material facilitado llevan implícito la heterosexualidad. Como ya se ha indicado se consideran las prácticas homosexuales como de riesgo para ser donante de semen. De confirmarse, serian descartados. Curiosamente nunca he oído en las consultas que se pregunte si la pareja masculina que acompaña a la mujer y que aportará el semen tiene prácticas homosexuales. Según el modelo androcéntrico, da identidad masculina pasa por una práctica del sexo medida por la cantidad en sus diversas variantes -más encuentros sexuales con el mayor número posible de mujeres - por una energía sexual irreprimible — medida sobre todo por los orgasmos, con el semen como "fluido mágico" que representa su culmen" (Osborne 2003: 240-241). Por el contrario, la sexualidad femenina aparece controlada. Los donantes de semen no deben tener problemas para la excitación sexual. Un donante en la entrevista comentaba que en ocasiones la eyaculación no era fácil.

Hay dos cosas que cortan un poco. Una que uno de los baños está en una habitación con fotos de críos que han nacido por la intervención de la clínica... no sé si por donantes... bueno eso corta bastante, estar al lado masturbándote con esas fotos de niños cerca, se te quitan las ganas. Ya sé que yo vengo a esto, a que las parejas tengan niños, pero para masturbarte debes quitarte eso de la cabeza. Otro problema son las revistas. Yo llevo cuatro meses viniendo y siempre son las mismas. Tengo un IPad y eso me ayuda. Si un día tardo mucho pienso que a lo mejor hay otros esperando. Eso me ponía nervioso los primeros días. Al salir miro a los hombres que están cerca y digo esos saben a lo que he venido aquí y a lo mejor mi semen es para ellos... es mejor no dar vueltas a para quién será. (Entrevista donante de semen AM octubre 2005).

Utilizando los conceptos de deseo y excitación sexual de Estupinyá (2013:62) "deseo es la motivación o interés por la actividad sexual, excitación es la respuesta física que acompaña a la actividad sexual", el donante no tiene interés o deseo por la masturbación en las clínicas, si bien si consigue tener una respuesta sexual, a veces no es tan fácil para ellos. Esto que resulta obvio no parece que se tenga en cuenta por parte de los receptores. Es frecuente escuchar en tono jocoso "es fácil para ellos ya que son jóvenes", "vienen y por hacerse una paja cobran unas pelas", "les pilla cerca de la universidad y en un momento se acercan y ganan un dinero" ${ }^{15}$. La hipotética

${ }^{15}$ Testimonios recogidos en charlas informales con profesionales, no grabadas y reconstruidas a base de notas, en la clínica C en Marzo de 2012. 
facilidad para la excitación sexual en los donantes merece matices, como hemos visto por sus testimonios.

En los centros consideran que el sentido más involucrado en la excitación sexual masculina es la vista, de manera que los hombres donantes son seres visuales en alerta constante a estímulos sexuales. Los centros A y B disponen de unas salas que preservan la intimidad para que los hombres puedan llevar a cabo la masturbación y obtener el semen. Se dispone de material pornográfico de revistas, películas e internet. Este material se dirige exclusivamente al deseo heterosexual. En el caso de la pareja masculina de la mujer receptora, esta puede entrar y ayudar en el proceso de la masturbación. Esta circunstancia no se contempla en el caso de los donantes de semen.

\section{LAS BUENAS PRÁCTICAS SEXUALES DEL DONANTE DE SEMEN Y DE LA DONAN- TE DE ÓVULOS. PRÁCTICAS DE RIESGO}

La homosexualidad masculina se relaciona con promiscuidad, considerada altamente contaminante y las relaciones homoeróticas, sobre todo masculinas, como "descuidadas" en el ámbito de la prevención y el cuidado sexual. La exclusión como donantes de semen de los hombres con hábitos homosexuales se justifica porque los coitos anales tienen mayor riesgo de contagio de infecciones de transmisión sexual. ¿Pero y el coito anal heterosexual? Las respuestas de los profesionales son un tanto ambiguas y no se descarta las prácticas de riesgo en hombres heterosexuales.En los centros B y C los donantes de semen deben firmar que no mantienen relaciones homosexuales. "Declaro que no he mantenido, ni mantengo, relaciones homosexuales, así como con personas infectadas de SIDA o con anticuerpos positivos para dicha enfermedad. No he utilizado drogas intravenosas o recibido transfusiones de sangre" (Historia clínica centro C). Los centros proporcionaron a la investigadora acceso a los consentimientos informados y a las historias clínicas de los y las donantes.

El sexo anal es una práctica más frecuente en la población masculina homosexual que en la heterosexual. A esto hay que añadir la promiscuidad que favorece las infecciones de trasmisión sexual. El coito anal favorece las infecciones por bacterias y por virus ya que la mucosa rectal es muy frágil y se lesiona fácilmente con la penetración del pene y de objetos. Claro que también pueden darse estas prácticas entre heterosexuales. El peligro es la posibilidad de infectar las muestras de todo el banco, a pesar de los controles. Debemos ser rigurosos y exigentes ya que en los bancos de semen, donde se almacenan numerosas muestras, se debe evitar el riesgo de contagio (Entrevista Ginecólogo CD, junio 2005).

Pero también se requiere monitorizar las eyaculaciones. La recogida de semen debe efectuarse tras un periodo de abstinencia sexual de 4 a 5 días ("más no, para que no estén viejitos los espermatozoides" decía una ginecóloga en consulta a una pareja).

El donante de semen, una vez aceptado, se compromete a realizar una donación semanal durante un periodo determinado que varía de 4 a 6 meses. Otro compromiso es no llevar a cabo prácticas consideradas de riesgo como punción intravenosa de drogas, contacto con personas portadoras de sida y no mantener relaciones homosexuales. Los donantes firman de manera precisa este compromiso. Además se comprometen a mantener cuatro días de abstinencia sexual, no eyaculación, previos a la 
donación de la muestra de semen. El caso de la donante de óvulos, debido a la manipulación corporal a la que es sometida estimulación y punción de los ovarios, las interferencias en las prácticas sexuales y anticonceptivas son mayores en relación a los donantes de semen. Debe suprimir cualquier método anticonceptivo, en el caso de que se les permita mantener relaciones coitales deben utilizar preservativo,siendo este obligatorio para evitar el embarazo y el contagio de enfermedades de transmisión sexual. En esta investigación, de un total de 33 donantes, 8 no utilizaban ningún método anticonceptivo, 8 preservativo masculino, 3 el método del calendario y/ o coitus interruptus. El resto, 9 debieron suspender anticonceptivos orales, 5 dispositivo intrauterino (DIU), previo a los tratamientos de estimulación de los ovarios ${ }^{16}$. Cuando la clínica permite las relaciones sexuales durante el tratamiento para algunas donantes es un inconveniente la utilización del preservativo (único método posible cuando la mujer está sometida a los tratamientos) ya que deben contar con la colaboración de su pareja y en ocasiones es difícil la negociación. "Es lo peor que lleva mi pareja, con el DIU nos iba bien, y ahora, a veces no se lo quiere poner (el preservativo) y terminamos enfadados" (Donante de óvulos AM Mayo 2004). Algunas clínicas indican la conveniencia de la abstinencia sexual durante el tratamiento y unos días tras la punción de los ovarios. En la página web del Instituto Valenciano de Infertilidad (IVI) disponen de un apartado sobre preguntas frecuentes en la donación de óvulos. Una de ellas "ipuedo mantener relaciones sexuales durante el tratamiento?». La respuesta es contundente, "Durante la estimulación ovárica hasta la nueva menstruación después de la punción folicular no es recomendable mantener relaciones sexuales, tanto por el riesgo de gestación múltiple como por el riesgo de torsión ovárica " ${ }^{17}$. La necesidad de la abstinencia sexual puede prolongarse de cuatro a seis semanas. En el centro D les permiten las relaciones sexuales con preservativo siempre y cuando todo esté bien y no tengan signos de que se esté produciendo alguna complicación. De ser así deben abstenerse de relaciones sexuales vaginales y acudir a la clínica para detectar y controlar el problema.

\section{AYUDAR A DAR VIDA. CAPTACIÓN Y PUBLICIDAD. COMO CONSEGUIR MATERIAL REPRODUCTOR}

En España ${ }^{18}$ la donación es un contrato gratuito, formal y secreto entre el donante y el centro autorizado, no tiene carácter lucrativo, el donante debe ser informado respecto a los fines de su donación, no se puede revelar la identidad del donante, la elección de los donantes debe garantizar similitudes fenotípicas con la mujer receptora y se debe asegurar que no nazcan más de seis niños por donante como se ha indicado anteriormente. Es perfectamente lícito que las clínicas de reproducción asistida lleven a cabo un proceso de publicidad para captar posibles donantes de semen y óvulos. ¿Cómo captan las clínicas a los y las donantes? ¿Qué sistema es más eficaz?

\footnotetext{
${ }^{16}$ Una informante debió suprimir la lactancia materna a su hijo para iniciar el ciclo de estimulación ovárica

${ }^{17}$ Se puede consultar en http://www.ivi.es/donantes/donantes-ovulos/ (Visitada en febrero de 2012).

${ }^{18}$ Real Decreto 412/1996 y la Ley 14/2006.
} 
Existen varios sistemas para captar donantes de semen y óvulos en función de la financiación del centro, privado o público, o por cuestión de género. En nuestra investigación se han captado mediante: anuncios publicitarios en papel o en la web de las clínicas, el "boca a boca", el reclutamiento por parte de la pareja, la "sensibilización" ante el problema de escasez de gametos. La tendencia actual, según señalaba una ginecóloga en la entrevista, es que sea más eficaz la captación a través de la publicidad en las páginas web de las clínicas "Ahora se meten en nuestra página y tienen toda la información antes de llamar. Los que acuden están bastante decididos a pasar por las clínicas y hacerse las pruebas" (Entrevista a ginecóloga AH enero de 2013). Los anuncios publicados en prensa o en carteles colocados en lugares estratégicos del campus universitario ${ }^{19}$ suelen llevar una imagen y un escueto mensaje aludiendo a la necesidad de donantes de semen y/u óvulos y un teléfono de contacto.

Mediante estos dos sistemas accedieron 14 de mis informantes, 10 donantes de semen y 4 donantes de óvulos. En España debido a la falta de un registro de donantes de gametos a nivel nacional, a pesar de que ya desde la primera Ley de Reproducción Asistida de 1988 se exigía que existiera una herramienta de este tipo, puede ocurrir que un donante acuda a más de un centro para donar su semen sin que sea posible conocer, por parte de la clínica receptora del semen, si ha sido donante en varias clínicas. En la Tabla 1 se puede ver la distribución de los sistemas de acceso en función de los centros y de sexos. Las páginas web de los centros privados ofrecen una información más detallada en cuánto a legislación, en qué consiste la técnica de donación de gametos, condiciones que deben cumplir los y las donantes, derechos y deberes, compensación económica y quienes son los beneficiarios del semen y los óvulos de donantes. Los centros de financiación pública carecen de este sistema de publicidad no existiendo ninguna referencia específica sobre la donación de gametos en la página principal del centro. En esta investigación 4 informantes hombres y 4 mujeres utilizaron la web para informarse del centro al que finalmente acudirían.

\begin{tabular}{|l|c|c|c|c|c|c|}
\hline \multicolumn{1}{|c|}{ SISTEMAS DE CAPTACIÓN } & $\begin{array}{c}\text { CENTRO A } \\
\text { semen }\end{array}$ & $\begin{array}{c}\text { CENTRO A } \\
\text { óvulos }\end{array}$ & $\begin{array}{c}\text { CENTRO B } \\
\text { semen }\end{array}$ & $\begin{array}{c}\text { CENTRO C } \\
\text { semen }\end{array}$ & $\begin{array}{c}\text { CENTRO D } \\
\text { óvulos }\end{array}$ & TOTAL \\
\hline Carteles en campus universitario & 4 & & 2 & 4 & & 10 \\
\hline Prensa & & 4 & & & & 4 \\
\hline Folletos en mano & & & & & & \\
\hline $\begin{array}{l}\text { Anuncios electrónicos o } \\
\text { web centro }\end{array}$ & 2 & 14 & & 3 & & 8 \\
\hline Boca a boca & & & & & 1 & 1 \\
\hline Sensibilización & 6 & 18 & 6 & 7 & 15 & 52 \\
\hline Reclutamiento por parte pareja & & & & & 10 \\
\hline TOTAL & & & & & & 10 \\
\hline
\end{tabular}

TABLA 1.-Acceso de los donantes de semen y de las donantes a los centros años 2002-2005, 2009 y 2013. Estos sistemas han sido utilizados por los informantes de esta investigación de ningún modo se pretende que sean extensivos a todos los donantes que acuden a los centros que se han investigado.

\footnotetext{
${ }^{19}$ En esta investigación se han observado tres universidades de la Comunidad de Madrid: Universidad Complutense de Madrid, Universidad Autónoma de Madrid y Universidad de Alcalá de Henares.
} 
El sistema "boca a boca" ${ }^{20} \mathrm{o}$ el/la donante-informante es un sistema de captación y canal de información directa entre donante previo/a y donante-aspirante. En este caso los que son o han sido donantes proporcionan información a un/a amigo/a y estos posibles donantes se dirigen a la misma clínica que su informante. Este sistema resultó eficaz para 19 informantes. En la clínica A las donantes-informantes de óvulos reciben una compensación económica por cada posible donante que aporten al centro. "Me enteré por una amiga, ella ya vino aquí, entonces me lo comentó todo como era lo que pagaban... a ella la dieron dinero por hacer publicidad conmigo" (entrevista donante de óvulos $\mathrm{CH}$, marzo 2005).

Con el que he denominado sistema de "sensibilización" quiero indicar que el o la donante ha tenido conocimiento del problema de escasez de gametos a través de experiencias de un amigo o un familiar. Deciden hacerse donantes para poder ayudar a personas que estén en situaciones similares a sus conocidos. A pesar de que es un relato frecuente en los discursos médicos la sensibilización ante la necesidad de gametos de donantes y el altruismo, solo una informante acudió a la clínica por este sistema. "Mi hermana lo pasó fatal ya que no podía quedarse embarazada así que yo me conciencié del problema y decidí ser donante. No fui a la clínica privada donde estuvo mi hermana ya que yo tenía claro que esto no lo hago por dinero...vine aquí (centro D) ya que no pagan por ser donante" (Entrevista donante óvulos, octubre 2009).

El reclutamiento o captación directa por parte de la pareja solo se produce en el centro D de financiación pública, la pareja debe aportar una donante de óvulos ${ }^{21}$. Para poder mantener el anonimato exigido por la legislación, la clínica forma grupos con un número determinado de parejas donante-receptora lo que permite hacer selección de compatibilidad inmunológica y física y poder llevar a cabo el intercambio. La receptora no recibe nunca los óvulos de la donante que aporta al grupo. La pareja consigue la donante o bien de su círculo social o familiar o bien anunciando por internet que buscan mujer que pueda donar sus óvulos. En la clínica D, 14 donantes de óvulos fueron captadas por la pareja, 10 entre el grupo de familiares (hermanas y primas) y 4 a través de anuncios en internet. En primer lugar suele elegirse la Red pero por este sistema la pareja tiene dificultades para conseguir donante. "Por Internet es muy difícil... hay mucha gente que necesita ayuda y es difícil conseguir donante...yo puse anuncios hace dos años, pero nada. Se lo he dicho a mi hermana que me ayude». (Mujer receptora de óvulos de donante LM, octubre 2009).

En los primeros meses del año 2013 comienza a percibirse un cambio importante en cuanto al volumen de mujeres y hombres que acuden a las clínicas con el objetivo de donar óvulos y gametos. También se observan cambios en el perfil de la donante desde el año 2011 siendo ahora mayor el número de españolas universitarias que acuden a los centros. En 2003-2005 el 60\% de las informantes eran extranjeras y un $87 \%$ trabajadoras de servicios. Todos los profesionales entrevistados en el año 2012 coinciden en que la crisis económica ha modificado el perfil socio-económico, sobre

\footnotetext{
${ }^{20}$ Denominación que se utiliza en las clínicas.

${ }^{21}$ En este sistema la pareja busca una donante, o bien de su grupo familiar o bien se pone en contacto a través de internet con una mujer que se ofrece como donante de óvulos. La pareja, generalmente la mujer, se encarga de acompañarla a la clínica, hacerse cargo de los gastos de la medicación y permanecer a su lado durante el periodo de reposo tras la punción.
} 
todo en el caso de las donantes de óvulos ${ }^{22}$. En la presente investigación no se han encontrado cambios significativos en el perfil socio-económico de los donantes de semen.

\section{LA SALUD SEXUAL Y REPRODUCTIVA DE LAS DONANTES.}

Semen, ovarios y útero de donantes se escinden de la unidad corporal convirtiéndose en herramientas al servicio de la biotecnología reproductiva y de los derechos reproductivos de los receptores. Los cuerpos de los y las donantes son tratados como objetos cuyos fragmentos son mercancías que se intercambian por bienes y cuya propiedad pasa a manos de los centros de reproducción. El cuerpo enajenado es objeto de transacción, de tráfico y de mercantilización. "Otro proceso de reducción del cuerpo y aún más radical es su fragmentación. El tratamiento del cuerpo como objeto sería el más riguroso, el que produce más eficazmente su cosificación, y hoy se destaca que con él se proporcionan más sistemáticamente unidades de circulación en el mercado como mercancías en el ámbito de la salud" (Velasco 2010: 230).

La fisiología de la reproducción concede distintos papeles a hombres y mujeres, pero es el cuerpo femenino el que emerge más sometido, como indican Díaz y González (2010: 33) “Disponer de semen es más fácil que manipular el órgano femenino interno en el que se producen los óvulos y se desarrolla el embrión. Pero los procesos no se dan en un mundo igualitario, sino en un mundo en el que se superponen distintos sistemas de jerarquización y explotación". Las TRHA pueden llegar a ocultar un trabajo reproductivo que cosifica a las mujeres. "El distinto papel de hombres y mujeres en la reproducción es un proceso evolutivo, la consideración social de estas mujeres es un producto de la transformación de las sociedades humanas en sistemas cada vez más eficaces de explotación" (Díaz y González 2010: 33).

La búsqueda de la rentabilidad biológica y económica por parte de las clínicas de reproducción asistida conduce a que se intente "forzar" la fertilidad de la donante de óvulos de manera que una o dos receptoras se beneficien de varios óvulos y aumente las posibilidades para ellas de embarazo. Esta rentabilidad provoca que, en ocasiones, los tratamientos provoquen vómitos, dolor de cabeza, dolor abdominal, que son denominados como "molestias" y, excepcionalmente, complicaciones más serias. Tres informantes tuvieron que suspender el tratamiento y ser atendidas por estas complicaciones. En las entrevistas señalan "Me duelen los riñones [...] tengo como dolor de regla". (Donante DA febrero de 2009) "lo peor fue al final de la ovulación, para mí fue doloroso [...] no poder andar, unos dolores, no contaba con ello" (Donante de óvulos AH, febrero de 2009). Es importante señalar que la donación de óvulos, a diferencia de la donación de semen supone interferencias en la vida social y familiar de la donante. Las visitas a la clínica pueden llegar a 20-22 y el día de la punción deben guardar reposo. Para las mujeres que trabajan esto es un problema ya que supone absentismo laboral, pedir permiso en los trabajos o bien utilizar su tiempo de descanso (Álvarez 2008).

${ }^{22}$ Entrevistas a cuatro ginecólogos de los centros A y D en marzo de 2013. Se toman notas no admiten el uso de grabadora. 
Los y las donantes ponen sus cuerpos al servicio de los receptores. Si bien es temporal, no se puede obviar el hecho de que sus relaciones afectivo-sexuales se ven afectadas ya que deben tener abstinencia sexual durante los tratamientos. En una entrevista una receptora de donante de semen comentaba el hecho de que el donante de semen tuviese que evitar eyaculaciones unos días previos a la donación: "No es para tanto, no creo que suponga un gran sacrificio...luego vienen aquí y ya está y los tres días siguientes pueden mantener todas las relaciones que quieran" (Receptora semen donante CG, febrero 2005). Los profesionales tampoco le conceden mayor atención "no es ningún problema para nuestros donantes de semen y óvulos" (Entrevista a ginecólogo CC, marzo 2013).

\section{CONSIDERACIONES FINALES}

La reproducción asistida procesa profundos anhelos, es una respuesta para personas con intensos deseos de acceder a la maternidad y a la paternidad. Las políticas de reproducción liberal, los avances en las técnicas, la popularización de las TRHA-D y la incorporación de nuevos grupos como parejas homosexuales, mujeres y hombres sin pareja y la senescencia reproductiva han incrementado la demanda de técnicas con donación de gametos. Captar donantes de semen y óvulos es una estrategia fundamental para los centros de reproducción asistida. El sistema es más eficaz en los centros de financiación privada que en la pública ya que aquellos disponen de recursos humanos y económicos destinados a este fin.

La abstinencia sexual y evitar prácticas de riesgo para los donantes de semen se convierten en la donante de óvulos en supresión de los métodos anticonceptivos habituales, negociar con su pareja el uso del preservativo, posponer unos meses la función genésica propia y, en muchos casos abstinencia de coito vaginal.

El sistema está establecido para satisfacer las necesidades reproductivas de hombres y mujeres a costa de "algunas mujeres" que aparecen como subordinadas y coaccionadas por un modelo reproductivo que pretende igualar a todos los grupos que acceden a la reproducción asistida, independientemente de la orientación sexual y la edad, pero que en realidad deja a ciertas mujeres en condiciones de poca elección. El uso simbólico del altruismo, matizado con la compensación económica, conduce a discriminación de género y de clase social. El donante de semen y la donante de óvulos pueden verse empujados en su acto altruista.

El número de aspirantes a donantes de semen y óvulos que se acercan a las clínicas de reproducción asistida está aumentando desde el año 2010 en la Comunidad de Madrid (España). El perfil social de las donantes de óvulos es el que ha sufrido mayor cambio, las mujeres que se interesan por ser donantes responden al prototipo de españolas y estudiantes universitarias. Para los informantes de esta investigación este incremento y cambio de perfil se debe a la crisis económica que afecta al país.

A modo de reflexión quiero indicar que uno de los hechos más sorprendentes de las técnicas de reproducción asistida es la incertidumbre en relación a los resultados de salud a largo plazo para las mujeres que se someten a tratamientos de estimulación ovárica. En concreto no existen informes detallados sobre las repercusiones en la salud de las donantes de óvulos. Coeytaux y Tober (2013) advierten del riesgo de carecer de suficiente información a este respecto: 
Esperamos que ahora que las donantes de óvulos (y ex donantes de óvulos) están hablando, los políticos y el público van a empezar a entender que los estudios completos sobre los efectos en la salud de la prestación de los óvulos, son esenciales para que las mujeres jóvenes tomen decisiones informadas. Mientras tanto, instamos a los medios de comunicación para dejar de enfrentar a las mujeres contra las mujeres y reconocer que se trata de tener suficiente información objetiva y basada en datos para poder tomar una decisión informada. Se lo debemos a todas las mujeres jóvenes que proporcionan los óvulos, ya sea para la fertilidad o para la investigación (Traducción propia).

\section{BIBLIOGRAFÍA CITADA}

Álvarez, Consuelo. 2008. La búsqueda de la eterna fertilidad. Altruismo y mercantilismo en la donación de semen y óvulos. Jaén: Alcalá Editorial.

Álvarez, Consuelo 2014. "La diversidad familiar y la divulgación de los orígenes genéticos a los niños nacidos a partir de donantes y/o gestación subrogada. IM-Pertinente 2(1): 17-43.

Aumont, Jacques. 1992. La imagen. Barcelona: Paidós

Bestard, Joan. (2004) Tras la biología: la moralidad del parentesco y las nuevas tecnologías de reproducción. Barcelona: Departament d'Antropologia Cultural i Història d'Amèrica i d'Àfrica Universitat de Barcelona.

Blake, Lucy; Polly Casey, Jennifer Readings, Vasanti Jadva y Susan Golombok. 2010. "Daddy ran out of tadpoles'. How parents tell their children that they are donor conceived, and what their 7 year olds understand". Human Reproduction 25(10): 2527-2534.

Butler, Judith. 2001. El género en disputa. México: Paidós

Coeytaux, Francine y Tober, Diane. 2013. "Eggs for Cash: Pitting Choice Against Risk”. Disponible en http://rhrealitycheck.org/article/2013/09/04/eggs-for-cash-pitting-choice-against-risk/ Fecha de acceso: 20 de mayo de 2015

Connell, Robert W. 1995. Masculinities. Cambridge: Polity Press

Daniels, Ken; Wayne Gillett, y Victoria Grace. 2009. "Parental information sharing with donor insemination conceived offspring a follow-up study". Human Reproduction 24(5): 1099-1105.

Díaz, Rodrigo y Aurora González. (eds) 2010. Naturalezas, cuerpos, culturas. Metamorfosis e intersecciones. México: Universidad Autónoma Metropolitana.

Edwards, Jeanette. 2005. “Make-up: Personhood through the Lens of Biotechnology". Ethnos 70(3): 413-43.

Enguix, Begonya. 2012. "Cultivando cuerpos, modelando masculinidades". Revista de Dialectología y Tradiciones Populares, LXVII (1): 147-180.

Estupinyá, Pere. 2013. S=EX2, La ciencia del sexo. Barcelona: Debate.

Fitó, Carme. 2010. Identidad, cuerpo y parentesco. Etnografía sobre la experiencia de la infertilidad y la reproducción asistida en Cataluña. Barcelona: Bellaterra.

Giddens, Anthony. 1991. Modernidad e identidad del yo. El yo y la sociedad en la época contemporánea. Barcelona: Península

González, Aurora. 2010. "Parentesco y género. Intersecciones y articulaciones”, en Virginia Fons, Anna Piella y María Valdés (eds.), Procreación, crianza y género: 335-358. Barcelona: Promociones y Publicaciones Universitarias.

Gramsci, Antonio. 1982. Cuadernos de la cárcel. México DF: Era.

Hammer, Joachim 1997. "Women and Reproduction" en Victoria Robinson and Diane Richardson, (eds.). Introducing women's studies: feminist theory and practice. New York: University Press.

Jociles, María Isabel y David Poveda. 2015. "El papel de las narrativas en la revelación de los orígenes en familias formadas a través de la donación de gametos". En David Poveda, María Isabel Jociles y Javier González-Patiño (comp.) Deseos, hadas, magos y semillas: Cuentos para comunicar los orígenes en familias que han acudido a la donación reproductiva: 4-9. Madrid: Infancia Contemporánea.

Jouannet, Pierre; Jean Marie Kunstmann, Jean Claude Juillard, Jean Luc Bresson, la Fédération française des CECOS. 2010. "La majorité des couples procréant par don de sperme envisage d'informer 
l'enfant de son mode de conception, mais la plupart souhaitent l'anonymat du donneur" en Pierre Jouannet et Roger Mieusset (coord.) Donner et après... La procréation par don de spermatozoïdes avec ou sans anonymat ?: 43-54. Springer-Verlag.

Ley 14/2006 de 26 de mayo, sobre técnicas de reproducción humana asistida. Sábado 27 de Mayo 2006, Boletín Oficial de España (BOE) no 126, España.

Miller, Cheryl. 2008. "Donated Generation". The New Atlantis: 227-44.

Nieto, José Antonio. 1990. "Antropología de la sexualidad. Erotofobia y erotofilia", en Joan Prat y Ángel Martínez (eds.), Ensayos de antropología cultural. Homenaje a Claudio Esteva-Fabregat: 357-366. Barcelona: Ariel.

Nieto, José Antonio. 1989. Cultura y Sociedad en las prácticas sexuales. Fundación Universidad Empresa.

Osborne, Raquel. 2003. "La organización de la sexualidad en Occidente: el papel de la institución en la prostitución". En Oscar Guasch y Olga Viñuales (eds). Sexualidades. Diversidad y control social: 235-257. Barcelona: Bellaterra.

Ragoné, Helena. 1994. Surrogate Motherhood: Conception in the Heart. Boulder: Westview Press.

Real Decreto 412/1996 de 1 de marzo, por el que se establecen los protocolos obligatorios de estudio de los donantes y usuarios relacionados con las técnicas de reproducción asistida y se regula la creación y organización del Registro Nacional de Donantes de Gametos y Preembriones con fines de reproducción humana. Sábado 1 de Marzo de 1996. Boletín Oficial del Estado (BOE) nº 72, España

Rohlinger, Deana. 2002. "Eroticizing men: Cultural Influences on Advertising and Male Objectification". Sex Roles 3 (4): 61-74

Shilling, Chris. 2005. The body in Culture, Technology and Society. Londres: Sage

Stolcke, Verena. 2004. "La mujer es puro cuento". Estudios Feministas, 12(2): 77-105

Strathern, Marilyn. 1992. After Nature: English Kinship in the Late Twentieth Century. Cambridge: Cambridge University Press.

Tober, Diane. 2001. "Semen as gift, semen as goods: reproductive workers and the market in altruism". Body \& Society 7(2-3): 137-160.

Tober, Diane. 2013.

Se puede consultar la noticia en http://www.geneticsandsociety.org/article.php?id=7136 (visitada el 9 de agosto de 2015)

Vance, Carol. 1991. "Anthropology Rediscovers Sexuality: A Theoretical Comment". Social Science and Medicine 33(8): 875-884.

Velasco, Honorio. 2010. Cuerpo y espacio. Símbolos y metáforas, representación y expresividad en las culturas. Madrid: Editorial Ramón Areces.

Vendrell, Joan. 2003. "Del cuerpo sin atributos al sujeto sexual: sobre la construcción social de los seres sexuales" en Oscar Guasch y Olga Viñuales (eds.), Sexualidades. Diversidad y control social: 21-43. Barcelona: Bellaterra.

Weston, Kath. 2003. "Estudios lésbicos y gays en el ámbito de la antropología", en José Nieto (ed.), Antropología de la sexualidad y diversidad cultural: 161-192. Madrid: José Talasa Ediciones.

Fecha de recepción: 7 de marzo de 2015

Fecha de aprobación: 26 de septiembre de 2015 